\title{
VARIATION IN METABOLISM OF BIOCHEMICAL TEST SUBSTRATES BY KLEBSIELLA SPECIES: AN EPIDEMIOLOGICAL TOOL
}

\author{
J. G. BARR \\ Department of Clinical Bacteriology, Royal Victoria Hospital, \\ Grosvenor Road, Belfast BT12 6BA, Northern Ireland
}

A моNG the Gram-negative aerobic bacilli Klebsiella spp. have been recognised as a major cause of hospital-associated infections. This has led to the development of typing methods for the purpose of improving epidemiological surveillance.

As an epidemiological tool, biochemical typing, by means either of conventional test methods (Rennie and Duncan, 1974) or of commercially available biochemical-test schemes (de Silva and Rubin, 1977), has been evaluated on its own and in combination with serological typing (Rennie and Duncan, 1974) and bacteriocine typing (Buffenmyer, Rycheck and Yee, 1976).

Reproducibility presents a problem in the biochemical typing of klebsiellae by means of conventional or commercially available systems (Butler, Lobregat and Gavan, 1975; de Silva and Rubin, 1977). It seems, however, that different genera may vary in respect of their metabolism of particular substrates (Rubin et al., 1976) in such a way that for individual genera or species particular biochemical tests contributing to non-reproducibility may be identified.

Among the klebsiellae, differences in the rate at which inositol is fermented have been associated with particular taxa (Barr and Mahood, 1976; Rubin et al., 1976) and slow fermentation of lactose by some isolates of Klebsiella pneumoniae (sensu lato) (see below) is widely recognised. Barr and Mahood (1976) found that a quantitative distinction could be drawn between the slow fermentation of inositol shown by certain klebsiellae and the rapid fermentation shown by others. In reduced substrate concentrations the slow fermenters failed to give a positive test result due to their inability to produce sufficient acid under such conditions. This approach was developed further here to study the differences in the metabolism of different test substrates shown by clinical isolates of Klebsiella spp. It was thought that the information gained might enable biochemical test reactions, especially those produced after short incubation periods, to be used as the basis of a " biochemical fingerprinting" of Klebsiella spp. by identifying the substrates for which the greatest variation in metabolism could be demonstrated. The possibility of exploiting this variation as an epidemiological tool in the differentiation of clinical klebsiella isolates was kept in mind.

\footnotetext{
Received 18 Feb. 1978; accepted 17 Apr. 1978.

J. MED. MICROBIOL.-VOL. 11 (1978)

501
} 


\section{MATERIALS AND METHODS}

Organisms. In this paper the terms Klebsiella pneumoniae (sensu stricto) and Klebsiella pneumoniae (sensu lato) will be used as defined previously (Barr, 1977). The strains examined from the National Collection of Type Cultures (NCTC) were as follows: $K$. pneumoniae (sensu lato), including $K$. aerogenes NCTC9668 and 8172, $K$. atlantae NCTC9496 and $K$. edwardsii NCTC5954; K. pneumoniae (sensu stricto) NCTC9633, 10246, 9632 and 204; Klebsiella ozaenae NCTC8883, 10313 and 9659. Eighteen clinical isolates, mainly derived from sputum, were obtained from Ruchill Hospital, Glasgow, and included 16 isolates of $K$. pneumoniae (sensu lato) of which four were classed as $K$. pneumoniae (sensu stricto), and two isolates of $K$. ozaenae. A further 234 isolates were obtained from various sources in the Royal Victoria Hospital, Belfast, over an extended period, and included $K$. pneumoniae (sensu lato) (216 isolates), K. pneumoniae (sensu stricto) (10 isolates) and $K$. ozaenae (eight isolates). The isolates of $K$. pneumoniae (sensu lato) included 17 biochemical types distinguished by the typing method of Rennie and Duncan (1974).

Media. All cultures were maintained on nutrient agar slopes and streaked on MacConkey's medium immediately before use.

Clinical isolates of Enterobacteriaceae were characterised by the methods described by Barr, Mahood and Curry (1977). Seven screening media were used. Aesculin Bile Agar (Difco), Simmons' Citrate Agar (Difco), Xylose Lysine Decarboxylase Agar (Difco) and Phenylalanine Agar (Difco) were prepared by the methods described by the manufacturers. Urease agar was prepared as described by Christensen (1946) with the modifications proposed by Cowan (1974); inositol-hydrogen-sulphide-motility agar and potassium cyanide agar were prepared as described by Barr and Mahood (1977), and ornithine decarboxylase agar was derived from the fluid medium of Fay and Barry (1972) by the addition of $1.5 \%$ Agar (Oxoid L11).

Klebsiella isolates were biotyped by the method of Rennie and Duncan (1974). However, the following biochemical tests were carried out by conventional methods as described by Cowan (1974) and where alternatives are given by Cowan (1974) the particular method followed is given in parenthesis: production of indole [method 2, with Tryptone 1\% (Difco)]; acetoin production (method 1; Barritt, 1936); utilisation of citrate [method 2, with Simmons' Citrate Agar (Difco)]; decarboxylase reactions with lysine and ornithine (method 1; Møller, 1955); utilisation of malonate (Shaw and Clarke, 1955); oxidation of gluconate (method 2; Carpenter, 1961); urease activity (method 1; Christensen, 1946). Aerobic acid-production from dulcitol, lactose and sucrose was tested in 1\% (w/v) Andrade's Peptone Water (Oxoid) Differentiation of biotypes was on the basis of the following three groups of test results: (group A) indole production, Voges Proskauer test, and citrate utilisation; (group B) lactose and sucrose fermentation, and malonate and gluconate utilisation: (group C) dulcitol fermentation, lysine and ornithine decarboxylation, and urease activity. Different reaction sequences in each group were identified by single-digit codes and the biotypes were recorded from the three biochemical test groups as three-digit codes.

Media for assessing differences in substrate metabolism. All sugar fermentations were carried out in Andrade's Peptone Water (Oxoid) supplemented with filter-sterilised sugar solutions of appropriate concentrations. Desired substrate concentrations of aesculin, citrate, malonate and urea were obtained by the addition of filter-sterilised solutions of each, in the appropriate broth base, to aesculin broth base (Cowan, 1974), Simmons' citratemedium base (Simmons, 1926) without agar, malonate phenylalanine-medium base (Shaw and Clarke, 1955) and urea-medium base without agar (Christensen, 1946) respectively.

Comparisons of substrate metabolism of klebsiella isolates were carried out in microtest plates (M24ART, Sterilin), with medium distributed in $25-\mu$ l or $50-\mu l$ volumes by means of a Minipipetter (Cooke Microtitre System; Dynatech Laboratories Ltd).

In a preliminary investigation, $50 \mu$ l of broth containing the highest substrate concentration $(2 \%, w / v$, in peptone water sugars) were placed in each well of the first row and $25 \mu \mathrm{l}$ of peptone water in each of the remaining wells. Six serial 2-fold dilutions of substrate in appropriate base, prepared by a Minidiluter (Cooke Microtitre System; Dynatech Laboratories Ltd), yielded substrate concentrations (w/v) of $2 \cdot 0,1 \cdot 0,0.5,0.25,0.125$ and $0.062 \%$. 
Similar dilution series in appropriate basal media were made with aesculin, citrate, malonate and urea, at initial concentrations of $0 \cdot 1,4 \cdot 0,0 \cdot 6$, and $0 \cdot 4 \%(w / v)$ respectively.

In later experiments, six portions of each basal medium were prepared, containing the carbohydrate substrates at concentrations corresponding to those obtained by the dilution procedure described above. For each concentration of each substrate, $50 \mu l$ of medium were placed in each of the 96 wells of a microtest plate.

Preparation of inocula, and inoculation. Inocula were prepared by transferring single colonies from 18-h cultures on MacConkey's medium into peptone water and incubating for $4 \mathrm{~h}$ at $37^{\circ} \mathrm{C}$ to produce a turbid culture of optical density $0.2-0.5$ at $700 \mathrm{~nm}$ as measured by a Hilger Spectrophotometer. Where required, serial 10-fold dilutions of this inoculum were prepared in 9-ml volumes of sterile distilled water.

Media for the identification and biochemical typing of klebsiella isolates (Rennie and Duncan, 1974; Barr et al., 1977) were inoculated with one drop $(0.02 \mathrm{ml})$ of a suspension containing $10^{7}-10^{9}$ colony forming units per $\mathrm{ml}$ (c.f.u. per $\mathrm{ml}$ ). For tests of substrate metabolism, inoculum suspensions $\left(10^{4}-10^{\circ}\right.$ c.f.u. per $\left.\mathrm{ml}\right)$ were dispensed in sterile microtest plates that served as templates, and inocula were transferred to the test plates with a 96-pin multipoint inoculator (Denley Instruments Ltd). When a series of six concentrations of substrate were tested in one plate, inoculum suspensions of each isolate were distributed in a corresponding row of six wells in the template. This allowed a maximum of 16 strains to be tested against six concentrations of one substrate on one plate. Normally, eight strains were tested in duplicate in a single plate.

When single concentrations of one substrate were tested on one plate, the inoculum template could be prepared with inocula of 96 individual isolates. Normally, however, 48 inocula were distributed in duplicate in the template. Templates were usually used to inoculate not less than two replicate plates of each substrate dilution series or single substrate concentration.

Conditions of incubation. Media for the identification and biochemical typing of klebsiella isolates were incubated in Replidishes (Sterilin) with the lids in the vented position. Lysine decarboxylase, ornithine decarboxylase and urease media were overlaid with sterile paraffin oil.

For tests of substrate metabolism, microtest plates, without lids, were placed inside sterile antibiotic-assay plates (Luckham Ltd) with the base lined with filter paper (Whatman 41; Whatman Labsales) and moistened with $25 \mathrm{ml}$ of sterile water. Control uninoculated dishes containing $1 \%(\mathrm{w} / \mathrm{v})$ lactose peptone water were included in some assay dishes to check sterility. The incubation period was $16 \mathrm{~h}$ at $37^{\circ} \mathrm{C}$ unless otherwise stated.

Recording of test results. Test results on media for the identification and biochemical typing of klebsiella isolates were recorded as described by Rennie and Duncan (1974) and Barr et al. (1977). In studies of the effect of substrate concentration, the utilisation of substrate was recorded according to the presence or absence of a change in the colour of the indicator.

Reproducibility of results. For the evaluation of reproducibility in the substrate utilisation tests, an inoculum template was prepared in a microtest plate by dispensing 48 strains in duplicate. The chosen concentration of each substrate under investigation was dispensed in each of four microtest plates. The four sets of duplicate results for each substrate were used to evaluate reproducibility within and between plates inoculated on the same day.

\section{RESULTS}

\section{Comparison of conventional biochemical-test results with results obtained at reduced substrate concentrations}

Conventional carbohydrate fermentation tests were used to detect klebsiella isolates that supported either more or less acid accumulation in test media than did the majority of isolates. The occurrence of slow fermentation of inositol, 
lactose or maltose in $1 \%$ peptone water could be shown to parallel an inability to produce acid at reduced substrate concentrations. Similarly, many isolates that demonstrated their greatest accumulation of acid in $1 \%$ peptone water could be shown to produce acid from substrate concentrations that were low compared with those required by the majority of isolates.

In the light of these observations, and those of Barr and Mahood (1976), it was decided to consider the rate of substrate utilisation as a function of the substrate concentration and to compare the metabolism of different substrates by klebsiella isolates by comparing their ability to yield a positive test result in a series of tests with decreasing substrate concentrations.

\section{Reproducibility of methods for substrate-metabolism studies}

The preparation of a substrate dilution series on a single microtest plate allowed a direct comparison of differences of strain metabolism of substrates to be made, and provided a useful screening method for the selection of substrate concentrations of value in strain discrimination. With this method, the results derived from replicate inoculations of individual strains were completely reproducible. Although less reproducible, the use of single substrate

\section{TABLE I}

Percentage of klebsiella isolates (48 in number) showing reproducibility of substrate-metabolism results within and between microtest plates on different test substrates*

\begin{tabular}{ll|cc}
\hline Substrate & $\begin{array}{c}\text { Concentration } \\
(\%) \\
\text { of substrate }\end{array}$ & \multicolumn{2}{c}{$\begin{array}{c}\text { Percentage of isolates showing } \\
\text { complete reproducibility }\end{array}$} \\
\cline { 3 - 4 } $\begin{array}{c}\text { within } \\
\text { plates } \dagger\end{array}$ & $\begin{array}{c}\text { between } \\
\text { plates } \ddagger\end{array}$ \\
\hline Adonitol & 0.5 & 100 & 88 \\
Dulcitol & 0.5 & 100 & 100 \\
Glycerol & 0.5 & 100 & 100 \\
Inositol & 0.5 & 98 & 100 \\
Sorbitol & 0.5 & 100 & 96 \\
Arabinose & 0.5 & 100 & 96 \\
Glucose & 0.25 & 100 & 98 \\
Lactose & 0.5 & 100 & 96 \\
Maltose & 0.25 & 96 & 83 \\
Rafinose & 0.25 & 100 & 100 \\
Rhamnose & 0.25 & 100 & 98 \\
Sucrose & 0.25 & 100 & 100 \\
Xylose & 0.25 & 100 & 98 \\
Aesculin & 0.025 & 100 & 100 \\
Salicin & 0.25 & 96 & 98 \\
Citrate & 0.1 & 96 & 87 \\
Malonate & 0.15 & 87 & 96 \\
Urea & 4.0 & & 81 \\
\hline
\end{tabular}

* Single substrate concentrations were distributed in each microtest plate.

$\dagger$ Reproducibility based on identity of duplicate results within each of four microtest plates.

$\ddagger$ Reproducibility based on identity of results between each of four microtest plates. 
concentrations distributed within one plate was preferred, for reasons of economy.

Careful standardisation of the test conditions was required to ensure the reproducible demonstration of differences in substrate metabolism. Variations in the inoculum suspension, between $10^{4}$ and $10^{9} \mathrm{c.f}$.u. per $\mathrm{ml}$, did not influence the test results, but it was necessary to standardise the inoculum preparation on MacConkey's medium, and to use only fresh 16-h cultures for the preparation of inoculum suspensions.

The reproducibility of the results derived from 48 strains within and between microtest plates on different test substrates was examined (table I). Reproducibility within microtest plates was based on the identity of duplicate results within each of four microtest plates. Complete reproducibility was obtained with all sugar and polyol substrates except inositol and maltose, and with the glucoside aesculin, while the least satisfactory reproducibility $(87 \%)$ lay in the demonstration of urea hydrolysis. Good reproducibility between plates was shown with the majority of sugars and polyols, and with aesculin and malonate; poor reproducibility between plates was found with tests for adonitol fermentation $(88 \%)$, maltose fermentation $(83 \%)$, citrate utilisation $(87 \%)$, and urea hydrolysis $(81 \%)$.

In view of the prevalence of multiple biotypes of klebsiellae in single clinical specimens observed by de Silva and Rubin (1977), the biochemical type and substrate metabolism of five well-isolated colonies derived from each of $\mathbf{4 0}$ clinical specimens were examined. Only in five specimens, three of which were derived from patients with tracheostomies, were multiple biotypes recorded. In each instance two biochemical types (Rennie and Duncan, 1974) were isolated.

\section{Influence of substrate concentration on biochemical-test reactions}

Polyols, sugars and glucosides. Klebsiella isolates differed in their ability to metabolise the majority of the 18 substrates examined (tables II, III and IV). Quite different results were obtained with the two substrates, aesculin and inositol, that have been used in the primary isolation of klebsiellae (Davis and Matsen, 1974) and in their differentiation from other Enterobacteriaceae (Chadwick, Delisle and Byer, 1974; Barr and Mahood, 1977). The absence of variation in the ability to metabolise aesculin establishes the value of this substrate, but the presence of wide variations in metabolism of inositol, and the failure to detect the fermentation of inositol by many isolates from a normal working concentration $(1 \%, w / v)$ of substrate, emphasises the limitations associated with the use of inositol for the differentiation of various klebsiellae.

Tests with all carbohydrate substrates, with the exception of arabinose, indicated considerable variation in substrate metabolism and in resulting acid accumulation. The results demonstrated that, for the majority of klebsiella isolates, the minimal concentration of substrate supporting acid production, under the conditions of the test, lay between $1 \%$ and $0.25 \%$; the results also identified the substrates allowing the greatest strain discrimination. As shown 
in tables II, III and IV, the best strain discrimination was obtained when sugar concentrations of $0.5 \%$ or $0.25 \%$, or polyol concentrations of $1 \%$ or $0.5 \%$, were employed.

With some substrates, the degree of acid accumulation at different substrate

TABLE II

Fermentation reactions of Klebsiella species and biotypes tested on different concentrations of polyol and glucoside substrates

\begin{tabular}{|c|c|c|c|c|c|c|}
\hline \multirow[b]{2}{*}{ 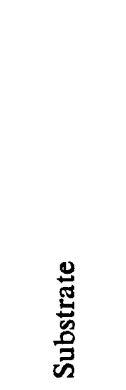 } & \multirow[b]{2}{*}{ 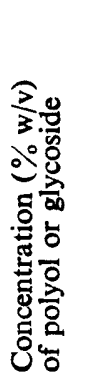 } & \multicolumn{5}{|c|}{$\begin{array}{l}\text { Percentage of positive reactions* shown by } \\
\text { the following klebsiella species and biotypes } \\
\text { (number } \dagger \text { of strains in parenthesis) }\end{array}$} \\
\hline & & 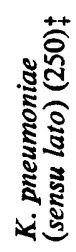 & 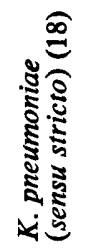 & 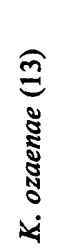 & 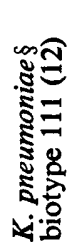 & 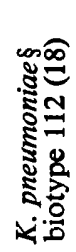 \\
\hline Adonitol & $\begin{array}{l}1.0 \\
0.5 \\
0.25\end{array}$ & $\begin{array}{l}96 \\
83 \\
16\end{array}$ & $\begin{array}{r}100 \\
83 \\
83\end{array}$ & $\begin{array}{r}100 \\
69 \\
38\end{array}$ & $\begin{array}{r}100 \\
92 \\
17\end{array}$ & $\begin{array}{r}100 \\
89 \\
6\end{array}$ \\
\hline Dulcitol & $\begin{array}{l}2.0 \\
1.0 \\
0.5\end{array}$ & $\begin{array}{l}98 \\
89 \\
35\end{array}$ & $\begin{array}{l}94 \\
94 \\
61\end{array}$ & $\begin{array}{r}100 \\
54 \\
0\end{array}$ & $\begin{array}{r}100 \\
100 \\
17\end{array}$ & $\begin{array}{l}\ldots \\
\ldots \\
\ldots\end{array}$ \\
\hline Glycerol & $\begin{array}{l}2.0 \\
1.0 \\
0.5\end{array}$ & $\begin{array}{l}96 \\
79 \\
11\end{array}$ & $\begin{array}{r}100 \\
100 \\
61\end{array}$ & $\begin{array}{l}92 \\
77 \\
23\end{array}$ & $\begin{array}{r}100 \\
83 \\
0\end{array}$ & $\begin{array}{r}100 \\
61 \\
11\end{array}$ \\
\hline Inositol & $\begin{array}{l}2.0 \\
1.0 \\
0.5 \\
0.25\end{array}$ & $\begin{array}{l}98 \\
97 \\
86 \\
25\end{array}$ & $\begin{array}{r}100 \\
100 \\
50 \\
11\end{array}$ & $\begin{array}{l}92 \\
69 \\
38 \\
15\end{array}$ & $\begin{array}{r}100 \\
100 \\
92 \\
42\end{array}$ & $\begin{array}{r}100 \\
100 \\
83 \\
6\end{array}$ \\
\hline Sorbitol & $\begin{array}{l}1.0 \\
0.5\end{array}$ & $\begin{array}{r}64 \\
4\end{array}$ & $\begin{array}{l}50 \\
44\end{array}$ & $\begin{array}{l}53 \\
53\end{array}$ & $\begin{array}{r}100 \\
8\end{array}$ & $\begin{array}{r}100 \\
0\end{array}$ \\
\hline Aesculin & $\begin{array}{l}0.025 \\
0.012\end{array}$ & $\begin{array}{r}100 \\
0\end{array}$ & $\begin{array}{r}100 \\
0\end{array}$ & $\begin{array}{r}100 \\
0\end{array}$ & $\begin{array}{r}100 \\
0\end{array}$ & $\begin{array}{r}100 \\
0\end{array}$ \\
\hline Salicin & $\begin{array}{l}1 \cdot 0 \\
0 \cdot 5 \\
0 \cdot 25\end{array}$ & $\begin{array}{l}44 \\
31\end{array}$ & $\begin{array}{r}100 \\
56 \\
44\end{array}$ & $\begin{array}{r}100 \\
61 \\
46\end{array}$ & $\begin{array}{r}100 \\
100 \\
58\end{array}$ & $\begin{array}{r}100 \\
100 \\
6\end{array}$ \\
\hline
\end{tabular}

* Results were recorded on the basis of the presence or absence of indicator colour change after $16 \mathrm{~h}$ incubation at $37^{\circ} \mathrm{C}$.

$\dagger$ For each substrate, the only isolates included were those that yielded a positive biochemicaltest result within 14 days' incubation at $37^{\circ} \mathrm{C}$ on conventional media under standard conditions.

$\ddagger$ The 250 isolates of $K$. pneumoniae (sensu lato) include the isolates of $K$. pneumoniae (sensu stricto) (18), K. pneumoniae biotype $111 \S(12)$ and $K$. pneumoniae biotype $112 \S(18)$ also shown independently in tables II, III and IV.

$\S K$. pneumoniae (sensu lato) biotype 111 (Rennie and Duncan, 1974) was characterised by: indole production; a positive Voges-Proskauer test; citrate, malonate and gluconate utilisation; dulcitol, sucrose and lactose fermentation; lysine decarboxylation and absence of ornithine decarboxylation; urea hydrolysis. $K$. pneumoniae (sensu lato) biotype 112 was differentiated from biotype 111 by absence of dulcitol fermentation. 
TABLE III

Fermentation reactions of klebsiella species and biotypes tested on different concentrations of sugar substrates

\begin{tabular}{|c|c|c|c|c|c|c|}
\hline \multirow[b]{2}{*}{ 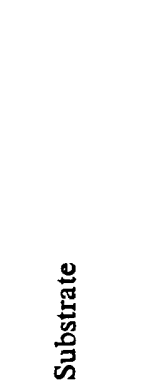 } & \multirow[b]{2}{*}{ 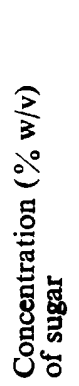 } & \multicolumn{5}{|c|}{$\begin{array}{l}\text { Percentage of positive reactions* shown by } \\
\text { the following klebsiella species and biotypes } \\
\text { (numbert of strains in parenthesis) }\end{array}$} \\
\hline & & 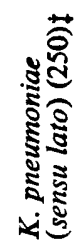 & 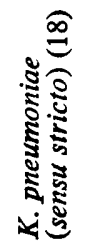 & 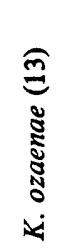 & 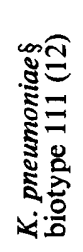 & 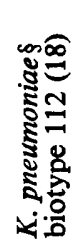 \\
\hline Arabinose & $\begin{array}{l}0.5 \\
0.25\end{array}$ & $\begin{array}{r}95 \\
5\end{array}$ & $\begin{array}{r}100 \\
0\end{array}$ & $\begin{array}{r}100 \\
0\end{array}$ & $\begin{array}{r}100 \\
8\end{array}$ & $\begin{array}{r}100 \\
0\end{array}$ \\
\hline Glucose & $\begin{array}{l}1 \cdot 0 \\
0 \cdot 5 \\
0 \cdot 25\end{array}$ & $\begin{array}{r}100 \\
100 \\
27\end{array}$ & $\begin{array}{r}100 \\
100 \\
61\end{array}$ & $\begin{array}{l}92 \\
92 \\
54\end{array}$ & $\begin{array}{r}100 \\
100 \\
42\end{array}$ & $\begin{array}{r}100 \\
100 \\
22\end{array}$ \\
\hline Lactose & $\begin{array}{l}1 \cdot 0 \\
0 \cdot 5 \\
0 \cdot 25\end{array}$ & $\begin{array}{l}99 \\
83 \\
33\end{array}$ & $\begin{array}{r}100 \\
100 \\
0\end{array}$ & $\begin{array}{r}100 \\
38 \\
0\end{array}$ & $\begin{array}{r}100 \\
100 \\
25\end{array}$ & $\begin{array}{r}100 \\
83 \\
22\end{array}$ \\
\hline Maltose & $\begin{array}{l}1 \cdot 0 \\
0.5 \\
0.25\end{array}$ & $\begin{array}{l}98 \\
96 \\
27\end{array}$ & $\begin{array}{r}100 \\
94 \\
39\end{array}$ & $\begin{array}{r}100 \\
100 \\
92\end{array}$ & $\begin{array}{r}100 \\
92 \\
0\end{array}$ & $\begin{array}{r}100 \\
89 \\
0\end{array}$ \\
\hline Raffinose & $\begin{array}{l}0.5 \\
0.25\end{array}$ & $\begin{array}{r}92 \\
5\end{array}$ & $\begin{array}{l}66 \\
33\end{array}$ & $\begin{array}{r}100 \\
69\end{array}$ & $\begin{array}{r}100 \\
8\end{array}$ & $\begin{array}{r}83 \\
0\end{array}$ \\
\hline Rhamnose & $\begin{array}{l}2.0 \\
1.0 \\
0.5 \\
0.25\end{array}$ & $\begin{array}{l}99 \\
98 \\
90 \\
22\end{array}$ & $\begin{array}{r}100 \\
100 \\
100 \\
56\end{array}$ & $\begin{array}{l}92 \\
92 \\
77 \\
38\end{array}$ & $\begin{array}{r}100 \\
100 \\
100 \\
58\end{array}$ & $\begin{array}{r}100 \\
100 \\
94 \\
28\end{array}$ \\
\hline Sucrose & $\begin{array}{l}0.5 \\
0.25\end{array}$ & $\begin{array}{r}100 \\
12\end{array}$ & $\begin{array}{r}100 \\
56\end{array}$ & $\begin{array}{l}77 \\
23\end{array}$ & $\begin{array}{r}100 \\
8\end{array}$ & $\begin{array}{r}100 \\
6\end{array}$ \\
\hline Xylose & $\begin{array}{l}0.5 \\
0.25\end{array}$ & $\begin{array}{r}100 \\
51\end{array}$ & $\begin{array}{r}100 \\
39\end{array}$ & $\begin{array}{l}92 \\
46\end{array}$ & $\begin{array}{r}100 \\
66\end{array}$ & $\begin{array}{r}100 \\
61\end{array}$ \\
\hline
\end{tabular}

$* \dagger \ddagger \S$ Footnotes as in table II.

concentrations could be shown to be associated with particular species or biotypes. Thus with the small number of $K$. ozaenae strains examined here, the accumulation of acid in reduced concentrations of maltose and raffinose contrasts with the documented slow fermentation of lactose (Cowan, 1974) and inositol (Barr and Mahood, 1976). Similarly, the isolates of $K$. pneumoniae (sensu stricto) examined could be differentiated from the majority of isolates of $K$. pneumoniae (sensu lato) by virtue of a reduced metabolism of lactose $(0.25 \%)$ and an enhanced metabolism of adonitol $(0 \cdot 25 \%)$, glycerol $(0.5 \%)$ and sorbitol $(0.5 \%)$. Less pronounced but distinct differences in substrate metabolism 
TABLE IV

Biochemical-test reactions of klebsiella species and biotypes tested on different concentrations of citrate, malonate and urea

\begin{tabular}{|c|c|c|c|c|c|c|}
\hline \multirow[b]{2}{*}{ 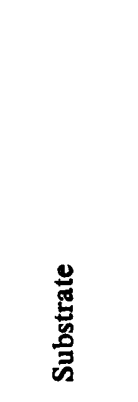 } & \multirow[b]{2}{*}{ 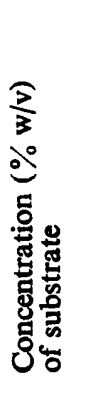 } & \multicolumn{5}{|c|}{$\begin{array}{l}\text { Percentage of positive reactions* shown by } \\
\text { the following klebsiella species and biotypes } \\
\text { (number } \dagger \text { of strains in parenthesis) }\end{array}$} \\
\hline & & 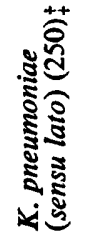 & 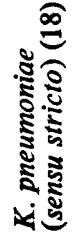 & 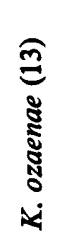 & 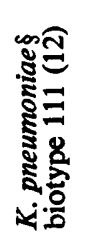 & 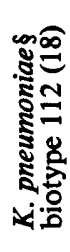 \\
\hline Citrate & $\begin{array}{l}0.4 \\
0.2 \\
0.1 \\
0.05\end{array}$ & $\begin{array}{r}96 \\
86 \\
58 \\
0\end{array}$ & $\begin{array}{r}100 \\
100 \\
75 \\
0\end{array}$ & $\begin{array}{r}100 \\
100 \\
50 \\
0\end{array}$ & $\begin{array}{r}100 \\
100 \\
25 \\
0\end{array}$ & $\begin{array}{r}100 \\
100 \\
66 \\
0\end{array}$ \\
\hline Malonate & $\begin{array}{l}0.6 \\
0.3 \\
0.15 \\
0.07\end{array}$ & $\begin{array}{l}97 \\
95 \\
85 \\
25\end{array}$ & $\begin{array}{r}100 \\
100 \\
100 \\
75\end{array}$ & $\begin{array}{l}\ldots \\
\ldots \\
\ldots \\
\ldots\end{array}$ & $\begin{array}{r}100 \\
100 \\
100 \\
25\end{array}$ & $\begin{array}{l}94 \\
94 \\
94 \\
11\end{array}$ \\
\hline Urea & $\begin{array}{l}4.0 \\
2.0 \\
1.0 \\
0.5\end{array}$ & $\begin{array}{l}41 \\
78 \\
99 \\
99\end{array}$ & $\begin{array}{r}33 \\
92 \\
100 \\
100\end{array}$ & $\begin{array}{r}30 \\
100 \\
100 \\
100\end{array}$ & $\begin{array}{r}61 \\
94 \\
100 \\
100\end{array}$ & $\begin{array}{r}42 \\
92 \\
100 \\
100\end{array}$ \\
\hline
\end{tabular}

between biotypes 111 and 112 (tables II, III and IV) of $K$. pneumoniae (sensu lato) were also observed particularly with salicin (table II).

The inability of some isolates to produce acid from substrate concentrations lower than that normally used (1\%) was demonstrated in respect of the majority of carbohydrate substrates examined. The large percentage of strains that failed to produce acid from $0.5 \%$ concentrations of many substrates suggests that for some klebsiella isolates acid production may be affected by small reductions in substrate concentration.

Malonate, citrate and urea. Considerable variation was observed in the detectable utilisation of malonate and citrate when substrate concentrations below normal working concentrations $(0.3 \%$ and $2 \%$ respectively) were used.

Urea hydrolysis was variable at a concentration of $4 \%$, i.e. twice the normal working concentration. Even at a concentration of $2 \%$ there was a number of negative reactions, whereas at lower concentrations the results were uniformly positive.

The results showed that variation in the utilisation of these three substrates was not useful in discriminating between species or biotypes. 


\section{Pilot application of substrate-metabolism tests to klebsiella strain differentiation}

Attempts to type klebsiella isolates by biochemical means (Rennie and Duncan, 1974) or by bacteriocine sensitivity (Buffenmyer et al., 1976) revealed the occurrence of a small number of types that represented the bulk of the populations examined.

In this study, isolates of biotypes 111 and 112 (see table II) of $K$. pneumoniae (sensu lato) were bacteriocine-typed by the method of Buffenmyer et al. (1976). However, each biotype yielded only two bacteriocine types of even distribution; this constitutes only a limited contribution towards further strain discrimination.

The results obtained in this investigation (tables I, II, III and IV) suggested that differential substrate metabolism might be made use of in an extended biochemical-typing scheme. The substrates were chosen on the basis of good strain discrimination and high reproducibility. The following were selected for use at the stated concentrations $(\% \mathrm{w} / \mathrm{v})$ : glucose $(0.25)$; glycerol $(1.0$ and $0.5)$; inositol $(0.5$ and 0.25$)$; xylose $(0.25)$.

The utilisation of these substrates at the stated concentrations allowed considerable discrimination to be made between isolates ascribed to biotypes 111 and 112 (tables II and III). Among 18 isolates of biotype 112, nine patterns of substrate metabolism were recognised, and among 12 isolates of biotype 111 a further seven patterns were distinguished. The reproducibility of this typing procedure was evaluated by typing 30 isolates on 4 successive days; the results were uniformly satisfactory.

\section{Discussion}

These findings confirm the value of aesculin in the primary differentiation of klebsiellae, reaffirm the previously reported variation in inositol fermentation (Barr and Mahood, 1976), and demonstrate the presence of variation in the metabolism of most other substrates examined. The observation that variation in metabolism of particular substrates may be characteristic of species or biotypes reinforces the view, expressed by de Silva and Rubin (1977), that certain biochemical tests may be responsible for the lack of reproducibility in the biotyping of different species. The observation that reductions in substrate concentrations affected the acid production from lactose and inositol by strains of $K$. ozaenae more than that of strains of $K$. pneumoniae (sensu lato) supports the reports of slow fermentation of lactose (Cowan, 1974) and inositol (Barr and Mahood, 1976) by K. ozaenae. The results shown in tables II, III and IV demonstrate that slow fermentation of other substrates by klebsiella isolates occurs at normal working concentrations. The test results given by such isolates are especially likely to be sensitive to small variations in substrate concentration and to other environmental factors that may influence growth and acid accumulation in 16-h cultures.

The failure to detect urea hydrolysis may in some instances have been due to inhibition, either of growth or urease activity, by normal or elevated concentrations of substrate. As in carbohydrate fermentations, it is likely that 
some isolates will show sensitivity to small variations in urea concentration in the region of the normal working concentration.

A possible application of variation in substrate metabolism to the biochemical typing of klebsiella isolates is suggested by the observations recorded here; it represents an approach resembling the "metabolic fingerprinting" proposed by Hedén (1974). Neither biochemical typing (Rennie and Duncan, 1974; de Silva and Rubin, 1977) nor bacteriocine-sensitivity typing (Hall, 1971; Buffenmyer et al., 1976) alone is sufficiently sensitive for epidemiological purposes. Serotyping (Edwards and Ewing, 1972) has been shown to complement biochemical typing (Rennie and Duncan, 1974). However, biochemical typing, if feasible, is an attractive tool that does not require the development of specific reagents or special methodology and can be integrated into bacterial identification regimens.

The observations reported provide a basis for the development of a sensitive system for the epidemiological surveillance of klebsiella infections. For a particular population of klebsiellae, it may be necessary to choose a combination of substrate-concentrations that will allow maximal strain discrimination. It is to be expected that the tests described here will be modified in future to give increased sensitivity.

\section{SUMMARY}

The variation in metabolism of biochemical test substrates by klebsiella isolates has been demonstrated. It is suggested that this variation is likely to result in false-negative reactions in biochemical tests incubated for short periods. The observations made may explain the reported difficulties in obtaining reproducible results in biotyping Klebsiella strains.

Preliminary work suggests that differences in substrate metabolism will provide a means of increasing the sensitivity of methods for the biochemical typing of Klebsiella spp.

The author wishes to thank Professor R. R. Gillies for constructive criticism of the paper and Mrs W. Booth for her careful preparation of the text.

\section{ADDENDUM}

Experience with several batches of Andrade's Peptone Water (Oxoid) has shown that small changes in reproducibility of substrate-metabolism results may be encountered between some manufacturers' batches.

\section{REFERENCES}

BARR, J. G. 1977. Klebsiella; taxonomy, nomenclature and communication. J. clin. Path., 30, 943.

BARR, J. G. AND MAHOOD, R. J. 1976. An assessment of inositol fermentation by klebsiellae and its implication in screening media. J. clin. Path., 29, 827.

BARR, J. G. AND MAHOOD, R. J. 1977. Complementary use of aesculin hydrolysis and inositol fermentation in the characterisation of klebsiellae. J. clin. Path., 30, 45. 
BARR, J. G., MAHOOD, R. J. AND CURRY, K. P. W. 1977. Factors affecting the value of a simple biochemical scheme for identifying Enterobacteriaceae: the reproducible recognition of biotypes. J. clin. Path., 30, 495.

BARRIT, M. M. 1936. The intensification of the Voges-Proskauer reaction by the addition of $\alpha$-naphthol. J. Path. Bact., 42, 441.

Buffenmyer, C. L., Rycheck, R. R. AND Yee, R. B. 1976. Bacteriocine (Klebocin) sensitivity typing of Klebsiella. J. clin. Microbiol., 4, 239.

Butler, D. A., Lobregat, C. M. AND GaVan, T. L. 1975. Reproducibility of the Analytlab (AP1 20E) system. J. clin. Microbiol., 2, 322.

CARPENTER, K. P. 1961. The relationship of the enterobacterium A 12 (Sachs) to Shigella boydii 14. J. gen. Microbiol., 26, 535.

Chadwick, P., Delisle, G. J. AND Byer, M. 1974. Biochemical identification of hospital enterobacteria by replica agar plating. Can.J. Microbiol., 20, 1653.

Christensen, W. B. 1946. Urea decomposition as a means of differentiating Proteus and paracolon cultures from each other and from Salmonella and Shigella types. J. Bact., 52, 461.

Cowan, S. T. 1974. Cowan and Steel's Manual for the identification of medical bacteria, 2nd ed. London.

Davis, T. J. AND Matsen, J. M. 1974. Prevalence and characteristics of Klebsiella species: relation to association with hospital environment. J. infect. Dis., 130, 402.

EDWARDS, P. R. AND EWING, W. H. 1972. Identification of Enterobacteriaceae, 3rd ed., Minneapolis, p. 294.

FAY, G. D. AND BARRY, A. L. 1972. Rapid ornithine decarboxylase test for the identification of Enterobacteriaceae. Appl. Microbiol., 23, 710.

Hall, F. A. 1971. Bacteriocine typing of Klebsiella spp. J. clin. Path., 24, 712.

HEDÉN, C. G. 1974. In New approaches to the identification of micro-organisms, edited by C. G. Hedén and T. Illéni, New York, p. 115.

MøLlER, V. 1955. Simplified tests for some amino acid decarboxylases and for the arginine dihydrolase system. Acta. path. microbiol. scand., 36, 158.

ReNNIE, R. P. AND DUNCAN, I. B. R. 1974. Combined biochemical and serological typing of clinical isolates of Klebsiella. Appl. Microbiol., 28, 534.

Rubin, S. J., Brock, S., Chamberland, M. ANd Lyons, R. W. 1976. Combined serotyping and biotyping of Serratia marcescens. J. clin. Microbiol., 3, 582.

Shaw, C. and Clarke, P. H. 1955. Biochemical classification of Proteus and Providence cultures. J. gen. Microbiol., 13, 155.

Silva, M. DE AND RUBIN, S. J. 1977. Multiple biotypes of Klebsiella pneumoniae in single clinical specimens. J. clin. Microbiol., 5, 62.

Simmons, J. S. 1926. A culture medium for differentiating organisms of typhoid-colon aerogenes groups and for isolation of certain fungi. J. infect. Dis., 39, 209. 